UDC 364:17

Nelli MELKONYAN

\title{
MECHANISMS OF OVERCOMING ETHICAL DILEMMAS IN NOWADAYS SOCIAL WORK
}

\begin{abstract}
In social work, ethical principles have been important in several key respects, with regard to the nature of its mission; the relationships that social workers have with clients, colleagues, and members of the broader society; the methods of intervention that social workers use in their work.

So, social work is situated between moral choice and professional ethical behavior, which allows orientating among the variety of moral requirements, evaluating activities taking into consideration morality and in this way it contributes to the cohesion and stability of social relations. However, the implementation of professional duties is often hampered by objective circumstances, and as a result a social worker can't always prevent the occurrence of ethical conflicts and facing ethical dilemmas.

In this article we'll discuss ethical conflicts of social work, which affect and determine the course of social assistance, social support at the present; it is also shown possible ways to overcome those ethical dilemmas.
\end{abstract}

Keywords: social work, ethics; professional duty, ethical decision-making; ethical dilemma, mechanisms of overcoming ethical dilemma

The social work, being a unique condition for a person and society, their development, perfection and self-realization, supposes comprehension of humanitarian motion. It's especially modern in current conditions, when flaring of human existence problems and undermining of values take place in the society undergoing a crisis. Humanitarian principles as outlook and behavior can become improvement guarantee, as humanitarian approach inspires people with faith for overcoming boundaries and promotes flexibility of problematic situations. So, moral mandatory, i.e. humanism, compassion, kindness, love, prosperity, social justice, human dignity, responsibility, are the cornerstones, on which social work is being constructed. Social workers promote social justice and the emergence of the desired changes. They are very sensitive and careful towards cultural and ethnic differences and are against any discrimination.

Traditionally, the values that are basic for social work are very important for its practice. These values distinguish social workers from the other professional groups. Values have several important attributes and perform several important functions: they are generalized, emotionally charged conceptions of what is desirable; historically created and 
derived from experience; shared by a population or a group within it; and provide the means for organizing and structuring patterns of behavior (Williams, 1968). In social work, ethical principles have been important in several key respects, with regard to the nature of its mission; the relationships that social workers have with clients, colleagues, and members of the broader society; the methods of intervention that social workers use in their work; and the resolution of ethical dilemmas in practice.

So, social work is situated between moral choice and professional ethical behavior. We should note that professional ethic has a huge importance on creation of social worker's moral knowledge, perceptions and demands, inner disposition, moral conscious (Medvedeva, 1999, pp. 39-40). It gives an opportunity for a person to combine own moral disposition with actions that are expected from social worker, helps orientate in moral demands and regulations diversity (Levy, 1973, pp. 34-42). On the other hand, professional ethic of social work systemizes the entire experience, generalizes and perfections it, contributing harmony and stabilization of social relationships. Moral regulation of social work guarantees protection and realization of social worker's rights and interests. However, the social work, interacting with different sides of human activity, can clash with contradictions and dilemmas during performance of professional duties.

In this article, social work's professionalethical conflicts or dilemmas are being examined, which affect and predict the process of social aid organization, as well as possible mechanisms of overcoming the latter are observed.
Logically, dilemma is a state, where choice of two possible contradictions is problematic and where the third possibility is excluded ("Encyclopedia of Social Work", 2008, p. 145). In everyday life, a person makes a choice from own values, persuasions and principles.

Ethical dilemmas in social work occur in three domains: relationships with clients in direct-practice settings (individuals, families, and small groups); social work involving "macro" practice, such as community practice (community organizing and advocacy), administration, management, and policy development and implementation; and relationships among professional colleagues.

These problems are often vague, uncertain and generate the diffidence, and the desire to ignore, to evade them. The most difficult situation for the social worker occurs because of the necessity of choosing between two or more relevant, but contradictory, ethical directives in a constantly changing world.

However, dilemmas occurring in social work are always connected with orientation values of the work. Urgency of the choice is conditioned with the fact that participant subjects of the work have different but equivalent interests, demands and values. Therefore, an ethical dilemma, by definition, is a circumstance which occurs only when two or more social work values are in conflict, i.e., an ethical dilemma involves a conflict between two or more ethical principles.

Ethical conflicts can be a reason of the very society's social-cultural, political, socialeconomic conditions. Studying social work's origin of morality and its scientific-methodic literature, we can distinguish a group of moral dilemmas, which are special for mainly all 
societies ("Encyclopedia of Social Work", 2008, pp. 145-146). They are the following:

Independence and manipulation: In social practice social workers use "indifference and resistance of a client" or "help the client realize the need to overcome the situation" expressions, however these are euphemisms directed to importance radicalization of social work in social consciousness. It can be considered as a form of manipulation, managing client's behavior, restriction of circles of activity and movement.

In similar situations, nevertheless, the main issue of restrictions of social worker by the advisee, the right to make decisions and the level of social worker's responsibility remain without comments. How can they trust the client with the latter?

And for that reason, it is important to restrict possibilities of conscious and behavior manipulations, in order to orient to client to display corresponding behavior. When the client's own values are in the center of their own attention, intensity of interference will decrease.

Professional paternalism and client selfdetermination: one of the key values for social work is the welfare and dignified existence of the client, which makes the main issue of paternalism modern. Paradigm of paternalism supposes a model of well-regarded relationships between the social worker and client. Tradition of social practice is that in each case social worker decides which client is kind. Supposedly, guided by client's best interest, paternalism gives an opportunity to restrict client's suicidal actions.

However, the issue of allowing the use of paternalistic approach is disputable in social practice and indefinite.
On one hand, client is a self-governing subject, who has to work, make decisions for life's improvement; on the other hand social worker is responsible for protecting the client from their own inadequate understanding of social reality.

In modern world, the mentioned above model decreases gradually, giving its place to interaction of building partnership approach. Client and social worker are observed as equal subjects and client is responsible for own life's improvement. Social workers respect and promote the right of clients to selfdetermination and assist clients in their efforts to identify and clarify their goals.

On the other hand, we shouldn't forget the level of client's workload issues, as a result of which the latter is displayed as cognitive, emotional and behavioral misfit. Social workers may limit clients' right to selfdetermination when, according to the social workers' professional judgment, clients' actions or potential actions pose a serious and imminent risk for clients themselves or for the others.

This is a difficult dilemma that is created by the social worker's desire to act in the client's best interest and the need to respect his right to act in a way that he feels is the best.

Credibility of moral conflict will decrease if social worker gets freedom, coming out of situation peremptory, orienting the client towards the path of overcoming, stressing that it doesn't suppose violation of advisee's rights, but creates grounds for productive realization.

Necessity to speak the truth: Truth is a necessary condition for social interaction and communication. Kant's study says that the truth is person's debt against oneself as a 
moral creature (Vasilenko, 2004, pp. 100101). Lying would mean demolishing human dignity in oneself. Balance of values cannot be predicted prior, only by the form of certain rules. However, it's always important to consider that the right of telling the truth is not a must. The social worker is responsible for providing the completeness, quality and timeliness information to the client. Informing the client is necessary in order to create favorable conditions for the revitalization of his personal potential. Besides, the lack of information might adversely affect the quality of the client's decisions, because without knowing all the facts and circumstances he can make a wrong decision, which will lead to the result which is opposite to the goal of social work and his personal interests.

It is the most important legal norm of person's immunity and a moral value in modern civil communities. On one hand receiving correct information about own state, prosperity and opportunities is the right of an client, on the other hand, however, in some cases it is so-called justified and even necessary to hide the truth or change with "savior lie", as the truth can put the entire staff into danger. In western practice of social work disposition is primary. Nevertheless, in moral point of view it's more correct to not tell a lie to the client using doctor's famous "placebo effect" and in the meantime keep high rank of morality in profession.

Privacy, confidentiality, and privileged communication: If the truth provides the intention and social interaction of the client and the social worker, then principle of secret (morality of social work supposes that it is social worker's obligation to respect client's individuality and to not voice information concerning the latter) is meant for keeping the cell of the society from participants with unauthorized intrusion. Social worker must guarantee the client this confidentiality and take all measures to ensure it.

Aim of silence, on the one hand, is to protect the trust of social worker towards the client, on the other hand, protection of civilians' legal rights.

Although it is always justified, but in some cases, for instance, trusted information is socially harmful, social workers have to observe, discuss the probability of identifying information given by the advisee. In order to avoid similar moral contradictions, it is necessary to inform the client about boundaries of secrecy in certain situations. In any case, this information can be conveyed only with the client's permission, and only the people who are involved in the solution of its problems.

Collegiality and awareness: In social practice there were cases, when social worker was obliged or consciously violated the law of an agency, where actions were taking place. In similar situation he/she makes the colleagues that are aware of the violation face moral choice. On one scale there are professional ethic norms, on the other one professional solidarity and loyalty, sense of friendship, authority and a threat of own position. Such kind of moral choice incites social workers to avoid uncovering and voicing about legal violations in their profession. While, it is social worker's obligation to perform professional responsibilities during similar situations, moving force of their activity has to be professional duty. In any case, the responsibilities of a social worker in a collegial relationship should be based on the professional courtesies of respect and fairness. 
Priority of law and interest protection of client: Solution to this dilemma is one of the main problems for social worker. Very often there are situations in social practice when state policy can cause damage to client, as it is not reflecting entirely the social life. This makes the social worker face another hard choice. Some consider fulfillment of any action permissible, and the aim is realization and protection of the client, nevertheless majority of social workers are guided by supremacy of the law. In order to avoid the mentioned above, it is important to present legislative changes concerning possibility of interest protection of client.

For example, a social worker may personally believe that a law that he is required to enforce is wrong. However, under the Constitution of the Republic of Armenia, he is required to obey all lawful and reasonable instructions to enforce that law unless there is good and sufficient cause to do otherwise.

Conflicts between personal and professional values: Commonly professional ethics refers to the ethics that a person must adhere to in respect of their interactions and business dealings in their professional life. Personal ethics refers to the ethics that a person identifies with in respect to people and situations that they deal with in everyday life. In some cases, personal and professional ethics may clash and cause a moral conflict.

Contradictions of personal and professional values are based on the mentioned moral inconsistencies. Social worker is an individual, civilian and as one, has a right for value orientations. Personal values are immanent to the profession and it is not always that the first system is harmonic and consistent to the second. For example, a social worker who holds certain religious or moral values about abortion may face an ethical dilemma when trying to assist a teen client who became pregnant and wishes to have an abortion.

Nevertheless, it's important for social worker to be guided by professional values and best interests of the client while protecting the latter. In each case, the social worker must think through the commitment to the client, colleague, profession, third parties. Moreover, social workers must constantly examine the nature of personal values and the ways by which these values have an impact on understanding the client's problems and social problems, and strategies.

In order to avoid similar difficulties the hierarchy of social worker's responsibilities is useful, which has developed by American social workers Lovenberg and Dolgoff ("Encyclopedia of Social Work", 2008, p. 147). According to their concept the social worker's decision should contribute to an individual's independence and personal development. The protection of human life has the highest priority over all other obligations of a social worker. The social worker's decision should contribute to improving the quality of human life and etc.

Certainly, the hierarchy of the social worker's duties fully resolves ethical dilemmas. It is an important guide which assists social workers in making decisions. Overcoming ethical dilemmas is a serious problem in a social work.

When writing an ethical dilemma paper or when attempting to resolve an ethical dilemma in practice, social workers should determine if it is an absolute or approximate dilemma; distinguish between personal and professional dimensions; and identify the ethical, 
moral, legal, and values considerations in the situation. After conducting this preliminary analysis, an ethical decision-making model can then be appropriately applied.

Ethical decision making is a process. There are many instances in social work where simple answers aren't available to resolve complex ethical dilemmas. Social workers should take into consideration all the values, principles, and standards of their profession that are relevant to any situation in which ethical judgment is warranted.

However, the future of social work cannot be predicted with precision, but it is certain that ethical and value issues will continue to permeate the profession. Hence, it will always be essential for social workers to examine these issues, which in the end form the very foundation of the profession.

Summing up, we should note that in social work ethical conflicts mentioned above constantly demand reproduction of handling mechanisms.

Professional culture and moral conscious of social worker can serve as basis for overcoming moral contradictions. The more educated the person, i.e. has professional subjective qualities, the richer the personal employment potential, hence the higher the professional activity quality. Ethic, moral knowledge, moral principles and values have their own place in social work's professional culture, which help orientating and avoiding possible conflicting and contradictory situations.
On the other hand a good social worker needs to be aware of the societal and professional values underlying his or her work so as to empower individuals, families and communities.

The realization of the issue mentioned above can make social worker's ethic upbringing possible, as the making of their professional important component.

\section{REFERENCES}

Encyclopedia of Social Work. (2008). Terry Mizrahi \& Larry E. Davis (Eds.). $20^{\text {th }}$ ed. Oxford.

Levy, C.S. (1973). The Value Base of Social Work. Journal of Education for Social Work. 9(1)

Medvedeva, G.P. (1999). Etika sotsial'noi raboty: (Ethic of social work, in Russian). Uchebnoe posobie dlya studentov vysshikh uchebnykh zavedenii. Moscow.

Reamer, F.G. (1990). Ethical Dilemmas in Social Service (Znd ed.). New York: Columbia University Press.

Vasilenko, N.Y. (2004). Osnovy sotsial'noi meditsyny (Basis of Social Medicine, in Russian) Vladivostok.

Williams, R.M., (1968). The concept of values. In D. L. Sills (Ed.), International Encyclopedia of the Social Sciences (Vol. 16, pp. 283-287). New York: Macmillan/Free Press. 